\title{
Impacts of precipitation and temperature on crop yields in the Pampas
}

\author{
Santiago R. Verón • Diego de Abelleyra • David B. Lobell
}

Received: 28 July 2014 / Accepted: 30 January 2015 /Published online: 21 February 2015

(C) Springer Science+Business Media Dordrecht 2015

\begin{abstract}
Understanding regional impacts of recent climate trends can help anticipate how further climate change will affect agricultural productivity. We here used panel models to estimate the contribution of growing season precipitation $(\mathrm{P})$, average temperature $(\mathrm{T})$ and diurnal temperature range (DTR) on wheat, maize and soy yield and yield trends between 1971 and 2012 from 33 counties of the Argentine Pampas. A parallel analysis was conducted on a per county basis by adjusting a linear model to the first difference (i.e., subtracting from each value the previous year value) in yield and first difference in weather variables to estimate crop sensitivity to interannual changes in P, T, and DTR. Our results show a relatively small but significant negative impact of climate trends on yield which is consistent with the estimated crop and county specific sensitivity of yield to interannual changes in P, T and DTR and their temporal trends. Median yield loss from climate trends for the 1971-2012 period amounted to 5.4\% of average yields for maize, $5.1 \%$ for wheat, and $2.6 \%$ for soy. Crop yield gains for this time period could have been 15-20\% higher if climate remained without directional changes in the Pampas. On average, crop yield responded more to trends in T and DTR than in P. Translated into economic terms the observed reductions in maize, wheat, and soy yields due to climate trends in the Pampas would equal \$1.1 B using 2013 producer prices. These results add to the increasing evidence that climate trends are slowing yield increase.
\end{abstract}

\section{Introduction}

It is increasingly important to understand the mechanisms responsible for the variability in agricultural production of Argentina as it becomes a significant national and international food

Electronic supplementary material The online version of this article (doi:10.1007/s10584-015-1350-1) contains supplementary material, which is available to authorized users.

S. R. Verón $(\bowtie) \cdot D$. de Abelleyra

Instituto de Clima y Agua, Instituto Nacional de Tecnología Agropecuaria (INTA), Repeto y Los Reseros SN (1686), Hurlingham, Argentina

e-mail: veron.santiago@inta.gob.ar

S. R. Verón

Departamento de Métodos Cuantitativos y Sistemas de Información, Facultad de Agronomía, Universidad de Buenos Aires and CONICET, Av. San Martín 4453, C1417DSE Buenos Aires, Argentina

D. B. Lobell

Department of Environmental Earth System Science and Program on Food Security and Environment, Stanford University, Stanford, CA 94305, USA 
supplier. Due to the extensive adoption of direct sowing, fertilizers, GMO's seeds and the expansion of agricultural area, grain production doubled - from 52 to $105 \mathrm{M}$ ton- between 1997 and 2012. In 2010 Argentina ranked second, third and ninth in maize, soy and wheat exports (FAO Stats) which represented the main source of foreign currency and an important source of tax revenues. A salient feature of this agricultural modernization was the central role of soy production whose area increased at an almost constant rate of 1 Mha per year. Soy supremacy came mainly at the expense of dairy and meat production in the major agricultural area - i.e., the Pampas region-and native forests in northern Argentina (Paruelo et al. 2005) which in turn altered relative food prices, raised environmental concerns, and spurred political conflicts (Grau et al. 2005, 2008).

Despite its relevancy, crop production in the Pampas remains highly dependent on weather as irrigation is still marginal (less than $1 \%$ on an area basis for sprinkler irrigation; INDEC 2002). As the realized impact of climate on crop yields integrates the response of crops to interannual weather variations as well as the climate trends, other gradual but directionallychanging variables might have gone under-recognized. For example, Lobell et al. (2011b) and Lobell and Burke (2008) showed that temperature had an important effect on national and regional long-term crop yields. However, at county level Maltais-Landry and Lobell (2012) found that precipitation, temperature and radiation had low contributions to wheat and maize yields. For Pampean counties, Verón et al. (2002) reported that mean annual temperature, precipitation from the first semester (summer and fall) and drainage explained $63 \%$ of the spatial variability in wheat mean above ground net primary productivity. Moreover, Magrin et al. (2005) attributed 38, 18 and $13 \%$ of maize, soy and wheat yield increase in 9 counties to changes in climate between 1950-1970 and 1971-1999. Lastly, Verón et al. (2004) found that the difference in wheat yield between 1923 and 2000 was positively associated with the average crop cycle precipitation and the photothermal quotient between September and November. In any case, our understanding of the climate-yield relationship is far from complete.

Methodologies to evaluate the impact of climate on crop yields span from process-based crop simulation models to statistical models of historical data (Lobell and Burke 2010; Shi et al. 2013). While the former integrates our best knowledge on crop physiology and reproduction, soil science, agronomy, and agrometeorology to predict how a crop will grow under different environmental conditions, they require detailed input data which restricts its extensive application, and also potentially omit important processes such as water logging. Statistical models are based on regression analysis of past crop yield and weather data which assesses the sensitivity of yield to interannual variations in, for example, precipitation or temperature by detrending raw data to account for non-weather effects (Lobell and Field 2007). As with crop simulation models, statistical models also suffer from disadvantages stemming from the extent of the spatial and temporal scale of the dataset, how the non-weather effects are removed, collinearity between regressor variables, and implicit assumptions about adaptation (Lobell and Burke 2010; Shi et al. 2013).

Previous studies at country level and global extent have highlighted the potential effects of future temperature increases on crop yields particularly for wheat and maize (e.g., Brisson et al. 2010; Lobell and Field 2007; Lobell et al. 2011b). In most cases, this finding was not primarily the result of higher crop sensitivity to temperature than to precipitation but of a larger change in past -and expected future- temperature than precipitation. County level studies can complement and deepen the understanding stemming from larger scale analyses given that, for example, particular climate-yield relationships may be obscured at country level and precipitation generally displays higher spatial heterogeneity than temperature. Additionally, county level information may provide insights on the role of socioeconomic features on the observed climate-yield relationship. 
In this study we evaluated the impact of climate temporal trends in wheat, maize and soy yield at the county level from 1971 to 2012 in the Pampas region of Argentina. We did so by means of time series and panel models constructed from crop specific yield and weather data. We aimed to i) describe the regional pattern of wheat, maize and soy yield and climate temporal trends ii) assess the sensitivity of yield to interannual changes in precipitation, temperature and the diurnal temperature range and iii) quantify the yield impact of these variables' trends for the 3 main crops in 33 counties of Argentina's most productive agricultural region.

\section{Methods}

\subsection{Climate and crop data}

We restricted our analysis to 33 counties from the Pampas region from which weather data (i.e., one weather station within each county) and crop data were available (a detailed description of the study area and cropping systems is available as Supplementary Materials). Daily minimum and maximum air temperatures and precipitation were taken from the archives from the Instituto de Clima y Agua-INTA which includes meteorological stations from INTA and the Servicio Meteorologico Nacional (SMN) of Argentina. Total precipitation (P in $\mathrm{mm}$ ), average temperature $\left(T\right.$, in ${ }^{\circ} \mathrm{C}$ ) and average diurnal temperature range (DTR, i.e., $T_{\max }-\mathrm{T}_{\min }$ in ${ }^{\circ} \mathrm{C}$ ) were calculated for each crop growing season and county from 1971 to 2013 . County level data of sown and harvested area (ha), yield ( $\mathrm{kg} / \mathrm{ha}$ ) and production (Ton) of wheat, maize, and soy from 1971 to 2013 were obtained from Ministerio de Agricultura Ganaderia y Pesca from Argentina (http://www.siia.gov.ar). To avoid possible artifacts generated by spatially interpolating data from a limited number of meteorological stations, we assumed that each weather station was representative of P, T and DTR experienced in the county where it was located. The study area accounted for roughly one third of the Argentinean maize, wheat and soy and encompassed 1, 0.77 and 5.1 Mha in 2012 (Figure S1). For the sake of clarity we will refer to each growing season by the initial year (thus 2012-2013 growing season will be refer as 2012).

\subsection{Climate and crop time trends}

First we assessed the time trends in weather variables and crop yields. Thus, we fitted a simple linear regression model to years from 1971 to 2012 and wheat, maize and soy growing season P, T, DTR and yield. Growing season P was calculated by adding daily values while for $\mathrm{T}$ and DTR we first calculated monthly means and then averaged across the growing season. Months with less than 3 days with data or years whereas county' harvested area was lower than 1000 ha were not considered. In turn, growing seasons with at least 1 month without P, T or DTR data were discarded as were counties with less than 30 years of paired weather and yield data. An alternate weather dataset requiring at least 12 days with data per month was tested as a sensitivity analysis but time trends were very comparable. We also check for possible effects available soil water at planting by considering precipitation from 1 month in advance to sowing dates. Crop yield time trends were also calculated from a dataset considering harvested areas higher than 10000 ha to check if our results were driven by unrepresentative situations. Finally, we fit the linear regression models to different start and end years to test if trends were dependent on the particular years considered. 


\subsection{Crop sensitivity to $\mathrm{P}, \mathrm{T}$ and DTR}

We then estimated the sensitivity of crop yield to P, T and DTR on a county basis by means of time series regression models. To avoid potential cases of heteroskedasticity we first $\log$ transformed yield data. Then, as done by others (e.g., Lobell and Field 2007) we removed climatic or yield trends by using the difference between each value and the previous year value (i.e., first difference regression models) to reduce the influence of longterm trends due to, for example, technological improvements or warmer or drying cycles. Finally, we applied the following model to assess the sensitivity of yield to year to year changes in P, T and DTR:

$$
\Delta \log Y_{i}=\beta_{0}+\beta_{P} \Delta P_{i}+\beta_{T} \Delta T_{i}+\beta_{D T R} \Delta D T R_{i}
$$

where $\Delta \log Y_{i}$ is the first difference in $\log$ yield of county $i, \beta_{0}$ is the intercept and $\beta_{P}, \beta_{T}, \beta_{D T R}$ represent the sensitivity of crop production to temperature and precipitation, and diurnal temperature range respectively. Because $\log \left(\right.$ yield $\left._{\text {year }}\right)-\log ($ yield year- 1$)$ is equal to $\log \left(\right.$ yield $_{\text {year }} /$ yield $\left._{\text {year- } 1}\right)$, the model's predicted sensitivities to $\mathrm{P}, \mathrm{T}$ and DTR are expressed as the $\%$ change in yield per $1 \mathrm{~mm}$ or $1{ }^{\circ} \mathrm{C}$ increase.

\subsection{Crop yield impact}

For comparison with the county-specific models, the impacts of P, T and DTR on crop yield were estimated by means of panel regression analysis. Similar to Lobell et al. (2011b), we developed a panel regression model of the form:

$$
\log \left(Y_{i, j}\right)=a_{i}+b \times y r+c \times y r^{2}+\beta \cdot X_{i, j}+\varepsilon_{i, j}
$$

where $\log \left(Y_{i, j}\right)$ is the logarithmic transformation of yield from county $i$ in the year $j$, yr stands for year, $a$ is a county fixed effects which accounts for differences in soils, management etc., $b$ and $c$ are the county specific linear and quadratic time trend respectively, $\beta$ is a vector of coefficients for the $X$ vector of variables (i.e., $\mathrm{P}, \mathrm{P}^{2}, \mathrm{~T}, \mathrm{~T}^{2}, \mathrm{DTR}, \mathrm{DTR}^{2}$ ) and $\varepsilon$ is the error term. By including linear or quadratic terms for time we detrended yield data thus accounting for the effects of factors other than weather (i.e., technological changes) upon yields. Additionally, the quadratic terms for $\mathrm{P}, \mathrm{T}$ and DTR reflect the fact that crops usually show an optimal range of these variables outside which yield tend to decrease (Jones et al. 2003; Lobell et al. 2011a). To avoid possible non-normal distributions of yield we used the logarithmic transformation (log yields).

Once calibrated, we ran the model with 5 different sets of weather data -1 for the observed values of P, T and DTR, 3 datasets for one detrended variable keeping the others "trended" and the last dataset with all 3 variables detrended. The procedure to generate the detrended weather variables consisted of four steps: 1) adjust a linear regression between observed weather and year (as done above), 2) compute residuals (i.e., the difference between each observed and predicted values), 3) calculate the initial value (i.e., corresponding to the first year of time series) by means of the adjusted linear model, and 4) add each year residual to the initial modeled value. The yield impact (\%) of each variable was quantified as the difference between predicted model yields with observed weather and predicted model yield with the detrended variable divided by predicted model yield with the detrended variable. The overall climate impact was similarly quantified by using the detrended P, T and DTR dataset. Lastly, on a per county basis we calculated the time trends of the differences between predicted model yield with observed weather and predicted model yield with detrended P, T, and DTR and then 
divided this trend by the overall yield trend per year. The resulting values represent the relative importance of climate to other technological and environmental factors influencing yields.

To account for the uncertainty in the relationship between yields and average growing season P, T and DTR because of the particular historical sample we resampled by bootstrapping the historical data 500 times and a new regression model was fitted into the data. Yield impact of climate trends were expressed as the median of the 500 regression models with a 5 and 95 percentile confidence interval.

Because of possible site specific climate impacts, we also estimated the yield impact of climate trends by means of the county specific first difference regression models. Therefore, we multiplied yield sensitivity to P, T and DTR (in \% by $1 \mathrm{~mm}$ or $1{ }^{\circ} \mathrm{C}$ ) by modeled change in P, T and DTR (i.e., multiplying the slope - in $\mathrm{mm}$ or ${ }^{\circ} \mathrm{C}$ per year- of the relationship between each weather variable and time by the amount of years elapsed between 1971 and 2013. We performed 500 bootstrap resampling datasets (on a per county basis) to which first difference regression models were fit. Yield impact estimated from county specific first difference models was expressed as the mean $\%$ change from these 500 models output and compared to the panel model yield impact estimates.

\section{Results}

\subsection{Yield and climate trends}

All crops showed significant yield increases in the selected counties between 1971 and 2012 (Figure S2). On average maize depicted the highest yield increase $\left(127 \mathrm{~kg} \cdot \mathrm{ha}^{-1}\right.$.year ${ }^{-1}$ or $2.9 \%$.year $\left.{ }^{-1}, n=29\right)$ followed by wheat $\left(42 \mathrm{~kg}^{-h^{-1}}\right.$.year $^{-1}$ or $1.9 \%$.year $\left.{ }^{-1}, n=32\right)$ and soy (34 kg.ha ${ }^{-1}$.year ${ }^{-1}$ or $1.5 \%$.year $\left.{ }^{-1}, n=16\right)$. Variability among counties in yield gains was higher for wheat $\left(0.14\right.$ to $3.5 \%$ year $\left.^{-1}\right)$ intermediate for soy $\left(0.3-2.2 \%\right.$.year $\left.{ }^{-1}\right)$ and lower for maize-ranging from 1.9 to $4 \%$.year ${ }^{-1}$.

In general, precipitation and temperature displayed positive temporal trends while DTR experienced almost equal increases and decreases through time. However, for P none of these increases was statistically significant while for T significant increases occurred in 14, 20 and 15 counties for wheat, maize and soy respectively. On the contrary, significant decreases in precipitation occurred in 2 counties for wheat, and 1 county for maize and soy. For DTR significant increases occurred in 7, 5, and 5 counties and significant decreases in 1, 4, and 3 for wheat, maize and soy respectively. To make trends comparable among counties with different mean temperature and precipitation, we normalized trends dividing the total trends for the 42 year period - e.g., ${ }^{\circ} \mathrm{C}$ per 42 years- by the standard deviation (SD) of the year to year fluctuations (Figure S3). Taking $2 \mathrm{SD}$ as a benchmark for comparison, increases exceeding this threshold were only found for T in 2, 1, and county for wheat, maize, and soy, and for DTR in 1 county for wheat.

\subsection{Yield sensitivity to interannual changes in weather}

Year to year changes in growing season weather (P, T and DTR) explained, on average, 40, 30 and $47 \%$ of the yield interannual variance in maize, wheat and soy. Weighted by production per county, wheat yield displayed a negative sensitivity to $\mathrm{P}\left(-0.004 \% . \mathrm{mm}^{-1}\right)$ while soy and maize sensitivity was 0.01 and $0.022 \% . \mathrm{mm}^{-1}$ respectively (Table 1 ). T and DTR sensitivities were always negative amounting to $-6,-6$ and -5.6 and $-3.7,-3.6,-3.5 \% .{ }^{\circ} \mathrm{C}^{-1}$ for wheat, 
Table 1 Average sensitivity of maize, wheat and soy to interannual changes in P, T and DTR, along with the coefficient of determination of the best-fit linear regression. Values correspond to percentage change in yield between each year and the previous year per 1SD or -between parenthesis- per $1 \mathrm{~mm}$ of $\mathrm{P}, 1^{\circ}$ of $\mathrm{T}$ or of DTR, weighted by production per county

\begin{tabular}{lllll}
\hline Crop & $P$ & $T$ & DTR & $\mathrm{R}^{2}$ \\
\hline Maize & $3.4(0.022)$ & $-3.4(-6.0)$ & $-3.9(-3.6)$ & 0.40 \\
Wheat & $-0.6(-0.004)$ & $-3.5(-6.0)$ & $-4.5(-3.7)$ & 0.30 \\
Soy & $1.6(0.010)$ & $-3.7(-5.6)$ & $-4.6(-3.5)$ & 0.47 \\
\hline
\end{tabular}

maize and soy respectively (Table 1). There was no clear N-S patterning T or DTR sensitivity for any crop (Fig. 1). In particular, counties exhibiting average yield losses higher than $10 \%$ per $1{ }^{\circ} \mathrm{C}$ warming were Rosario, Rio Cuarto, Marcos Juarez, Castellanos and San Cristobal for wheat, and Rosario for maize. Soy highest sensitivity to T occurred in San Pedro and amounted to $9 \%$ per $1{ }^{\circ} \mathrm{C}$. Sensitivities higher than $10 \%$ per $1{ }^{\circ} \mathrm{C}$ increase in DTR were only found in soy crops in General Obligado. Slightly positive sensitivities to DTR were found in 9 de Julio for wheat and San Cristobal for soy.

Consistent positive $\mathrm{P}$ effects on yields-implied from confidence intervals not crossing the 0 yield sensitivity-, were found in 2 counties for wheat, 7 for maize and 3 counties for soy respectively (Fig. 1). Consistent negative $\mathrm{P}$ effects on wheat yields were only found in Castellanos and Obligado. Contrastingly, no positive yield effect was found for $\mathrm{T}$, while 21,15 and 11 counties displayed consistent negative sensitivities to $\mathrm{T}$ for wheat, maize and soy respectively. Similarly, sensitivities to DTR were consistently negative in 12,10 and 4 counties for wheat, maize and soy. Expressed as percentage of yield difference per standard deviation, sensitivities were lowest for $\mathrm{P}(-0.6,3.4$ and $1.6 \%$.SD), intermediate for $\mathrm{T}(-3.5,-3.4,-3.7 \%$.SD) and highest for DTR $(-4.5,-3.9,-4.6 \% . \mathrm{SD})$ for wheat maize and soy respectively (Table 1$)$.

Correlations between DTR and T or P add to the difficulty in the assessment of each factor's relative importance. The magnitude of negative correlations was higher and more frequent for $\mathrm{P}$ and DTR than for P and T. Correlations between DTR and T were positive, although weak, for wheat.
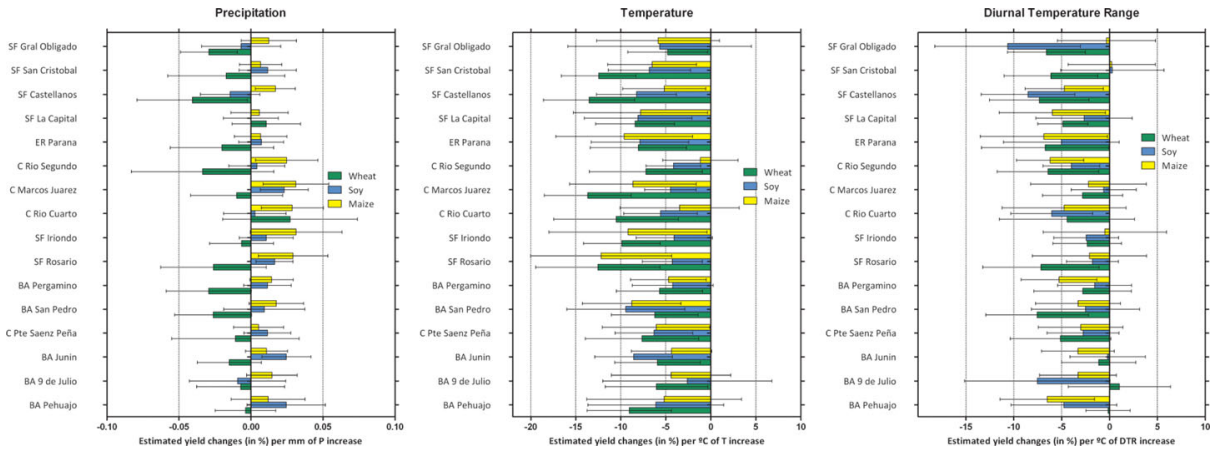

Fig. 1 Slopes of the first-differences in Log. yield vs first-differences in P and T and DTR (for the 16 common counties among crops). Error bars show the 5-95\% confidence interval. Counties are ordered in a north (upper) - south (lower) direction 


\subsection{Yield impact of climate trends}

Climate trends from 1971 to 2012 had negative impacts across the 3 crops as estimated by the panel models (Table 2). Considering all counties, median maize loss amounted to $5.4 \%$, wheat lost 5.1 and soy $2.6 \%$ compared to what would have been produced if climate remained without directional changes (Fig. 2). Considering the average Pampas production of the last 10 years, each year these loses would equal to a 1, 0.98 and 0.62 MTn of maize, wheat and soy. County-specific impacts were most notably in Iriondo, Rio Segundo, Marcos Juarez, and Rosario where wheat yield loss exceeded $10 \%$. For maize, this decreased was only found in Iriondo while in Tandil, Suarez, San Pedro, Pergamino, Rosario, Uruguay, Marcos Juarez Parana, Castellanos, San Cristobal and Obligado yield impacts ranged between 5 and $9 \%$. Four counties (Pergamino, Rio Segundo, Iriondo and Obligado) experienced soy yield reductions between 5 and $8 \%$. Positive impacts of climate trends on yield occurred in a few counties: Saenz Peña, Bolivar, Puan, Pueyrredon and Villarino for wheat; Pueyrredón and Bolivar for maize, and Pehuajo, Rio Cuarto, and Saenz Peña for soy. These positive impacts were higher than $5 \%$ only in Saenz Peña soy crops.

Most of the impacts were driven by T trends with DTR and P having crop-site-specific impacts (Fig. 2). On average, negative impacts of $\mathrm{T}$ trends were higher for maize, followed by wheat and soy (Table 2) while DTR impacts were approximately an order of magnitude less negative with maize yield decreasing by $0.49 \%$, wheat by 0.4 and soy $0.15 \%$. P trends, in turn, reduced maize and wheat by 0.28 , and $1.85 \%$ while soy yields were increased by $0.11 \%$. In general, T and DTR had opposite effects, negative for the former and positive for the latter.

Expressed relative to the observed yield gains in the 1971-2012 period - a way to weight how much of the overall increase in yields was due to climate trends or other factors such as genetic or management practices-maize, wheat and soy displayed different magnitudes (Fig. 3). Wheat yield gains could have been $21.5 \%$ higher if T DTR or P trends had not taken place. Furthermore, for maize and soy yields gains could also have been 14 and $20 \%$ under the same scenario. There was not a clear spatial pattern of changes in yield gains.

Climate trend impacts modeled with county-specific first difference models showed qualitative similar results (Figure S4). For example, maize and wheat reductions amounted to 4.6 and $5.8 \%$ and soy reductions remained the lowest (1.9\%). Correlations between yield impacts estimated by a single panel or by county specific models varied from 0.76 (wheat), 0.55 (soy) and 0.47 (maize). Most notably differences in maize yield impact due to the type of model used occurred in Rosario, Capital (where local first differenced model estimated a higher negative impact than that of the panel model) and in Maraco (where the local model estimated positive and panel model negative impacts). Wheat yield impact estimated by local models also were higher than panel model estimates in Rosario and Parana and showed positive impacts in Uruguay compared to the negative impacts expected from panel model results. For soy, Obligado and 9 de Julio were the counties with the highest difference in climate trends impacts on yield -Obligado being the county where the local model estimated higher negative

Table 2 Median estimates of the impact of P, T and DTR trends from 1971 to 2012 on maize wheat and soy yields

\begin{tabular}{llllll}
\hline Crop & $P$ & $T$ & DTR & T \& P & T, P \& DTR \\
\hline Maize & -0.28 & -4.64 & -0.49 & -5.08 & -5.37 \\
Wheat & -1.85 & -3.14 & -0.15 & -3.28 & -5.09 \\
Soy & 0.11 & -2.30 & -0.40 & -2.68 & -2.58 \\
\hline
\end{tabular}



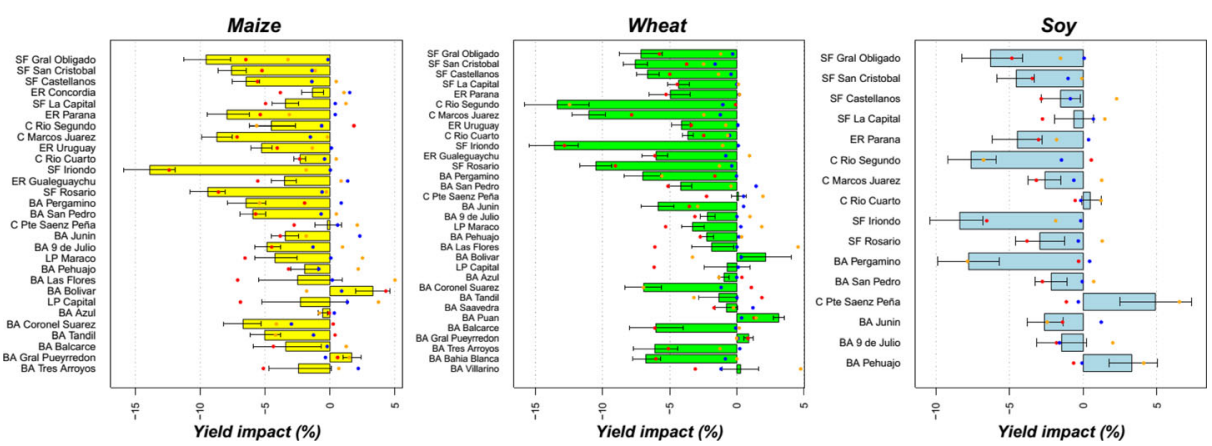

Fig. 2 Estimated net impact of trends in P, T and DTR on crop yields as percent change in average yield. Bars show median estimates and error bars display the 5 and 95 quantiles. Counties are ordered in a north (upper) south (lower) direction. Red, orange and blue dots show median estimate of impact for T, DTR and P trend, respectively

impacts and 9 de Julio with positive instead of negative impacts when local model replace panel model estimates.

The sensitivity tests performed to evaluate whether results were dependent on the choice of harvested area threshold or the starting and ending years of the studied period suggest that reported results are robust. For example, Figure S5 shows that there are no systematic effects of advancing or postponing dates on P, T or DTR trends. Only a few counties changed from positive to negative trends when moving the start and ending years and in these cases the absolute values were still close to zero. Similarly, using county yield data from growing seasons where more than 10000 has (instead of 1000 has) were harvested did not result in a qualitative different outcome (Figure S6). Lastly, overall differences due to the use of a climate dataset extending from one month prior to sowing as a proxy for the effects of soil water availability at planting on yield were less than $0.50 \%$ (Table S1).

\section{Discussion}

Crop yield and yield trends are key aspects for food production and agricultural land requirement with important consequences in food security and ecosystem's sustainability (Foley et al. 2011; Grassini et al. 2013). Yield trends can derive from genetic improvements,
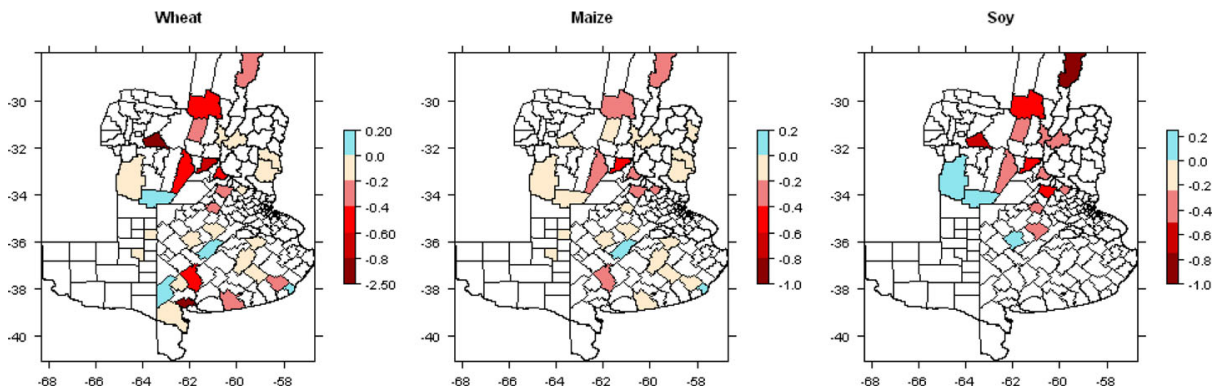

Fig. 3 Estimated net impact of the overall P, T and DTR trends on counties' maize wheat and soy yields, divided by the yield trends observed between 1971 and 2012 
changes in management practices and climate together with their interactions (Anderson and Hazell 1989). We here focused on the effects of climate on maize, wheat and soy yield trends between 1971 and 2012 in the Argentine Pampas. Our results indicate a relatively small but significant negative impact of climate on yield which is consistent with the estimated crop and county specific sensitivity of yield to interannual changes in $\mathrm{P}, \mathrm{T}$ and $\mathrm{DTR}$ and their temporal trends. Translated into economic terms the observed 5.4, 5.1 and $2.6 \%$ reductions in maize, wheat, and soy yields due to climate trends in the Pampas would equal \$1.1 B using 2013 producer prices. This lost equals ca. $5 \%$ of 2013 Argentinean grain exports.

Our results showed that, on average, climate trends reduced the observed yield trends over this time period by 15-20\%. These estimates contrast with the positive contributions of changes in climate reported by Magrin et al. (2005); Asseng et al. (2012)and de la Casa and Ovando (2014). Differences in the studied area, time frame considered, and the methodology used may explain this disagreement. For example, Magrin et al. (2005) analyses included a subset of the counties used in our study while Asseng et al. (2012) focused on the western sub humid margin of the Pampas and de la Casa and Ovando (2014) conclusions refer to the province of Cordoba, although only part of it is agricultural. Differences in the time period considered in each study -1950-1999 Magrin et al. (2005), 1941-2010 de la Casa and Ovando (2014) and 1937-2005 Asseng et al. (2012) - may be the reason for the differences between time trends in the weather variables observed among studies. The three studies reported an increased in water availability which was put forward as the main cause for higher yields or improved agricultural suitability. In turn, Magrin et al. (2005) suggested that observed increases in minimum temperature together with the decrease in maximum temperature and solar radiation also benefited yields. Contrarily, we found that Pampas growing season climate trends since 1971 were dominated by an increase in average temperature, which had a negative impact on yields, and a more mixed pattern in DTR and P. In addition, Maltais-Landry and Lobell (2012)compared two modeling approximations (simulation models as used by Magrin et al. (2005) and Asseng et al. (2012), and statistical models as used here) and found that simulations models like DSSAT tended to overestimate precipitation importance. Similar to the current study, (Brisson et al. 2010) proposed that climatic trends may have neutralized the beneficial effects of genetic improvements upon wheat yields and, together with agronomic practices, may have been responsible for the yield stagnation in France occurred along the last two decades. Many studies concerning yield trends have divided the sources between genetic and management improvements usually reporting approximately equal contributions (Cardwell 1982; Duvick 2005; Fischer and Edmeades 2010). Our results suggest that nonweather contributions (i.e., genetic improvement, pest and weed control, fertilization, irrigation, and sowing and harvesting dates among other) should have been more important than previously reported in order to compensate for the negative climatic impacts.

Variation across counties in climatic impacts on yield trends can be explained by differences in observed yield gains, climate trends or different crop yield sensibilities to changes in climate. For example, it is clear that the extreme negative values, like wheat in Bahia Blanca or soy in Gral. Obligado, were a consequence of very low yield gains $(\sim 2$ and $18 \mathrm{~kg} /$ ha year respectively). However, other important negative impacts were observed in counties with average yield gains like wheat and soy in Rio Segundo and maize in Iriondo. In these counties T and DTR increases were among the highest found which, together with the negative sensitivities of yield to increases in T and DTR, explains why modeled yields without trends were higher than observed yields. The mechanisms involved in the negative impacts of increased temperature and DTR include the acceleration of development stages, reduced photosynthesis and increased respiration (Jones et al. 2003). In turn, yield responses to changes 
in DTR may be due to the positive association between DTR and irradiance (Bristow and Campbell 1984) or because plants respond differently to changes in daily maximum and minimum temperatures. Higher DTR with increased $\mathrm{T}$ means that maximum temperatures increased more than minimum temperatures which may be associated to increased water stress or reduced photosynthesis. This reinforcing effect of higher DTR and $\mathrm{T}$ seems to be responsible for the negative impact in Iriondo, San Cristobal and Rio Cuarto for the 3 crops together with the decreases in $\mathrm{P}$ for wheat and soy. Alternatively, increasing DTR with decreasing $\mathrm{T}$ as occurred in Coronel Suarez, Bolivar and Rio Segundo, imply a reduction in minimum temperature more important than the reduction in maximum temperature which could be particularly harmful for wheat due to frost occurrence and for soy because of pod setting reduction (Calviño et al. 2003; Hume and Jackson 1981). Lastly, increases in P can benefit crops by reducing water stress, increasing nutrient uptake and photosynthesis. However, for wheat and maize the overall contribution of $\mathrm{P}$ trends to yield was negative, perhaps due to higher disease incidence or flooding events in wheat or reduced irradiance in maize.

In agreement with the results of the panel model, our first difference analyses showed that, on average, crop yield responded more to $1 \mathrm{SD}$ in changes in T and DTR than in P. An intriguing result was that $\mathrm{C}_{3}$ and $\mathrm{C}_{4}$ species did not differ much in their sensitivity to $\mathrm{T}$. Given warming trend across the Pampas, a much higher sensitivity of wheat and soy would have been expected as these $C_{3}$ species are more vulnerable to photorespiration than the $C_{4}$ maize. However, much of the negative impacts of $\mathrm{T}$ in maize are not related to photorespiration, but to increased water stress (Lobell et al. 2013). Results from the correlation analysis between the first differences in weather variables showed that DTR and P were highly associated across counties for the 3 crops, $\mathrm{T}$ and $\mathrm{P}$ were almost not associated while $\mathrm{T}$ and DTR were associated in roughly half of the counties for maize and soy and only in 5 for wheat. Thus, the relative importance of interannual changes in each variable upon crop yield may be biased due to the observed collinearity. In any case, P, T and DTR explained between 30 and $50 \%$ of the variance in year to year yield changes which highlight the importance of other variables not considered in this analysis.

Results presented here should be interpreted with caution. The accuracy of national crop production datasets -as the one used here- may have skewed our results (Paruelo et al. 2004; Sadras et al. 2014). However, the implications of different data reliability should be lower for time trends analyses than for average yield estimates (Sadras et al. 2014). In addition, as any model, our regression analyses do not take into account possible management adaptations such as changes in sowing date or crop varieties. More importantly we did not consider particular temperature or precipitation events -or its intra seasonal timing- which could have pronounced effect on yield. We did, however include two of the most important dry spells of the century in the Pampas which occurred in 2008-2009 and 2011-2012. Additionally, further checks on whether considering a single sensitivity of crop yield to each weather variable across all counties (panel model), harvested area threshold, or the start and ending years considered, suggest that our results are robust. Lastly, we note that we have not included the effect of rising $\mathrm{CO}_{2}$ which has been estimated to be $0.065 \%$ per ppm. increase for $\mathrm{C}_{3}$ crops (Ainsworth et al. 2008). Thus, between 1971 and 2012 the effect would have increased wheat and soy yields by roughly $3.3 \%$.

Acknowledgments Our work is funded by the Agencia Nacional de Promoción Científicay Tecnológica of Argentina (ANPCyT PICT0598) and the Instituto Nacional de Tecnología Agropecuaria (PNNAT-1128024). SRV thanks INTA Programa de Capacitación for the visiting fellowship at Stanford University, during which this work was conducted. 


\section{References}

Ainsworth EA, Leakey ABD, Ort DR, Long SP (2008) FACE-ing the facts: inconsistencies and interdependence among field, chamber and modeling studies of elevated [CO2] impacts on crop yield and food supply. New Phytol 179:5-9

Anderson JR, Hazell P (1989) Variability in grain yields. The John Hopkins University Press, London

Asseng S, Travasso MI, Fulco L, Magrin GO (2012) Has climate change opened new opportunities for wheat cropping in Argentina? Clim Change 117:181-196

Brisson N, Gate P, Gouache G, Oury F, Huard F (2010) Why are wheat yields stagnating in Europe? A comprehensive data analysis for France. Field Crops Res 119:201-212

Bristow KL, Campbell GS (1984) On the relationship between incoming solar-radiation and daily maximum and minimum temperature. Agric For Meteorol 31:159-166

Calviño P, Sadras VO, Andrade FH (2003) Development, growth and yield of late-sown soybean in the southern Pampas. Eur J Agron 19:265-275

Cardwell VB (1982) Fifty years of Minnesota corn production: sources of yield increase. Agron J 74:984-990

de la Casa AC, Ovando GG (2014) Climate change and its impact on agricultural potential in the central region of Argentina between 1941 and 2010. Agric Forest Meteorol

Duvick DN (2005) The contribution of breeding to yield advances in maize (Zea mays 1.). Adv Agron 86:83-145

Fischer RA, Edmeades GO (2010) Breeding and cereal yield progress. Crop Sci 50:S85-S98

Foley JA et al (2011) Solutions for a cultivated planet. Nature 478:337-342

Grassini P, Eskridge KM, Cassman KG (2013) Distinguishing between yield advances and yield plateaus in historical crop production trends Nat Commun 4 doi:10.1038/ncomms 3918

Grau HR, Aide TM, Gasparri NI (2005) Globalization and soybean expansion into semiarid ecosystems of Argentina. Ambio 34:265-266

Grau HR, Gasparri NI, Aide TM (2008) Balancing food production and nature conservation in the Neotropical dry forests of northern Argentina. Glob Chang Biol 14:985-997

Hume DJ, Jackson AKH (1981) Pod formation in soybeans at low temperature. Crop Sci 21:933-937

INDEC INdEyC (2002) Censo Nacional Agropecuario. Buenos Aires

Jones JW et al (2003) The DSSAT cropping system model. Eur J Agron 18:235-265

Lobell DB, Burke MB (2008) Why are agricultural impacts of climate change so uncertain? The importance of temperature relative to precipitation. Environ Res Lett 3:034007

Lobell DB, Burke MB (2010) On the use of statistical models to predict crop yield responses to climate change. Agric For Meteorol 150:1443-1452

Lobell DB, Field CB (2007) Global scale climate-crop yield relationships and the impacts of recent warming. Environ Res Lett 2:004000

Lobell DB, Banziger M, Magorokosho C, Vivek B (2011a) Nonlinear heat effects on African maize as evidenced by historical yield trials. Nature Clim Chang 1:42-45

Lobell DB, Schlenker W, Costa-Roberts J (2011b) Climate trends and global crop production since 1980. Science 333:616-620

Lobell DB, Hammer GL, McLean G, Messina C, Roberts MJ, Schlenker W (2013) The critical role of extreme heat for maize production in the United States Nature Climate Change 3:497-501

Magrin GO, Travasso MI, Rodriguez GR (2005) Changes in climate and crop production during the 20th century in Argentina. Clim Chang 72:229-249

Maltais-Landry G, Lobell DB (2012) Evaluating the contribution of weather to maize and wheat yield trends in 12 U.S. counties. Agron J 104:301-311

Paruelo JM, Guerschman JP, Baldi G, Di Bella CM (2004) La estimación de la superficie agrícola. Antecedentes y una propuesta metodológica. Interciencia 29:421-427

Paruelo JM, Guerschman JP, Verón SR (2005) Expansion agricola y cambios en el uso del suelo. Ciencia Hoy 15: $14-23$

Sadras VO, Grassini P, Costa R, Cohan L, Hall AJ (2014) How reliable are crop production data? Case studies in USA and Argentina Food Security

Shi W, Tao F, Zhang Z (2013) A review on statistical models for identifying climate contributions to crop yields. J Geogr Sci 23:567-576

Verón SR, Paruelo JM, Sala OE, Lauenroth WK (2002) Environmental controls of primary production in agricultural systems of the Argentine Pampas. Ecosystems 5:625-635

Verón SR, Paruelo JM, Slafer GA (2004) Interannual variability of wheat yield in the Argentine Pampas during the 20th century Agriculture. Ecosyst Environ 103:177-190 